\title{
Neuropsychological aspects of the rehabilitation of patients with paralysis from a spinal injury who also have a brain injury
}

\author{
W Strubreither, B Hackbusch, M Hermann-Gruber, G Stahr and HP Jonas \\ ${ }^{1}$ Rehabilitation-Centre Häring of the Austrian Workers Compensation Board, 6323 Bad Häring, Austria
}

\begin{abstract}
In order to examine the rehabilitation process of patients suffering from a severe spinal cord injury and who also have a cerebral injury, 322 patients with paralysis from a spinal injury were subjected to neuro-psychiatric and neuro-psychological examinations. On average $20.2 \%$ of these patients showed an associated cerebral lesion. The psychological results of such cerebral lesions are summarized under the concept of the so-called organic psychic syndrome (OPS). In $27.7 \%$ of these patients no organic psychic syndrome resulted, and in these patients a conventional paralysis rehabilitation could be carried out. $41.6 \%$ showed very minor to moderate injuries, with $30.7 \%$ being severely disabled from the cerebral injury. Rehabilitation for these patients was modified, using new therapeutic approaches, and also traditional therapeutic methods adapted to the abilities and needs of this patient group. In $25.5 \%$ of the patients there was no substantial improvement during the treatment period of initial rehabilitation $(\mathrm{x}=12.5$ weeks for the treatment of cerebral injury); but in $36.2 \%$ of the patients there was substantial improvement and in $38.3 \%$ full remission of organic psychic disorders occured. Improvements in this sphere have a direct bearing on the rehabilitation capacity of this patient group.
\end{abstract}

Keywords: paraplegia; tetraplegia; cerebral lesion; organic psychic syndromes

\section{Introduction}

When considering the specialist literature in recent years it is apparent that a large percentage of patients with transverse spinal paralysis also have an associated head injury. The percentages range from $18 \%$ to $73 \% .^{1-8}$ Decisions of the necessity to adapt traditional rehabilitation measures for spinal paralysed patients may only be drawn on the basis of these figures with reservations. The reasons for this are twofold:- With a few exceptions ${ }^{7}$ there is no classification according to the type or level of severity of the head injuries. Neither injuries to the facial part of the skull nor contusion of the head or concussion of the brain with full recovery lead to secondary injuries which require special rehabilitation methods in a rehabilitation centre for spinal paralysed patients; this is in complete contrast to the situations where there are secondary injuries resulting for example from cerebral contusion. However, there are a series of studies where traumas which lead to full recovery and those which possibly cause cerebral injuries are summarized.

There are studies ${ }^{1,2,4,5,7,8}$ which only give an account of skull-brain traumas; a cerebral lesion associated with spinal cord paralysis does not, however, necessarily result from direct trauma (such as cerebral

Correspondence: W Strubreither contusion, cerebral compression, subdural, epidural or intra-cerebral haematoma, etc.); secondary factors, such as cerebral oedema, metabolic injury or injuries caused by hypoxia, anoxia; tertiary causes resulting from long periods spent in intensive care (with caloric deficiency, endocrine disorders, etc.); and quaternary causes such as embolic or inflammatory processes may damage the brain.

Direct trauma is usually diagnosed in the acute stage; cerebral lesions resulting from secondary causes are diagnosed occasionally and only partially. As far as tertiary and quaternary injuries are concerned, the proportion of cases diagnosed is even smaller. All patients with a serious spinal injury will have a degree, sometimes very severe, of psychological trauma as well as the physical neurological disability. The purpose of this study should not be to emphasize the well-known psychic reactions to a spinal cord injury, but to examine the effects of psychic disturbances with cerebral, organic causes, the so-called organic psychic syndrome (OPS), of spinal paralysed patients, who also have a cerebral injury.

\section{Sample}

In the rehabilitation centres of the Austrian Workers' Compensation Board (AUVA) spinal paralyzed patients, who have been diagnosed as having a cerebral 
lesion, or who are suspected as having one, undergo a neuro-psychiatric and neuro-psychological examination at the outset of their rehabilitation, with follow-up examinations. The AUVA rehabilitation centre Häring ( $\mathrm{RH})$ is equipped for paralyzed patients, but also for the treatment of patients with cerebral lesions (Table 1).

On average over the last 3 years about a fifth of the patients beginning rehabilitation had a cerebral lesion in addition to spinal paralysis. The causes of this compound injury are found in Table 2. The distribution of the age and gender of the patients are shown in Figure 1. The causes of cerebral lesions are shown in Table 3 (diagnosis on admission).

\section{Methods}

As a standard procedure at $\mathrm{RH}$ all patients with spinal paralysis are examined for a possible cerebral lesion, with both neurological-psychiatric and clinical psychological examinations. The most serious problem for rehabilitation is a possible organic psychic syndrome (OPS). OPS means the psychological results of a

Table 1 Number of spinal paralysed patients with an associated cerebral lesion during the period 1993-1995

\begin{tabular}{lccc}
\hline & $\begin{array}{c}\text { Paralysis/ } \\
\text { initial rehabilitation }\end{array}$ & $\begin{array}{c}\text { Proportion with an } \\
\text { associated cerebral } \\
\text { lesion }\end{array}$ & $\begin{array}{c}\text { \% with a } \\
\text { compound injury }\end{array}$ \\
\hline 1993 & 95 & 13 & $13.7 \%$ \\
1994 & 105 & 25 & $23.8 \%$ \\
1995 & 122 & 27 & $22.0 \%$ \\
Total & 322 & 65 & $20.2 \%$ \\
\hline
\end{tabular}

Table 2 Causes of a combined injury of spinal paralysiscerebral lesion

\begin{tabular}{lcc}
\hline & $\mathrm{n}$ & $\%$ \\
\hline Road accident & 31 & 47.7 \\
Fall & 15 & 23.1 \\
Suicide attempt & 7 & 10.8 \\
Illnesses & 6 & 9.2 \\
Other & 6 & 9.2 \\
& 65 & 100 \\
\hline
\end{tabular}

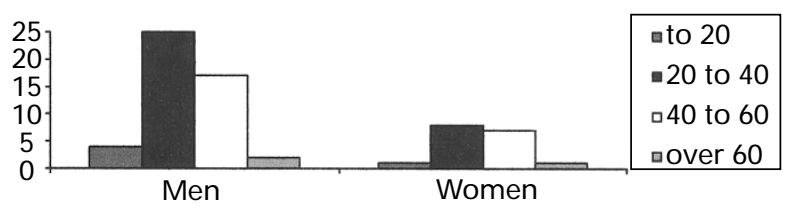

Figure 1 Age and Gender distribution of spinal paralysed patients with an associated cerebral lesion cerebral lesion after the acute phase. The disturbances include performance disorders (memory, thinking, sensorimotor, concentration) and personality disorders (drive, emotionality, general type). The disorders found at onset of rehabilitation are shown in Table 4.

Alongside this qualitative differentiation a further breakdown was made according to the degree of

Table 3 Causes of cerebral lesions in spinal paralysed patients

\begin{tabular}{lcc}
\hline & $\mathrm{n}$ & $\%$ \\
\hline Cerebral contusion/compression & 33 & 50.7 \\
Sub-,epidural,intra-cerebral haematoma & 14 & 21.5 \\
ARDS, Hypoxia & 11 & 17.0 \\
Illness & 4 & 6.2 \\
Other & 3 & 4.6 \\
& 65 & 100 \\
\hline
\end{tabular}

Table 4 Psychic disorders with cerebral organic causes within organic psychic syndrome (OPS)

\begin{tabular}{|c|c|c|}
\hline & $\mathrm{n}$ & $\%$ \\
\hline \multicolumn{3}{|l|}{ 1. Performance: } \\
\hline \multicolumn{3}{|l|}{ Memory } \\
\hline \multicolumn{3}{|l|}{ (Performance in storage process } \\
\hline \multicolumn{3}{|l|}{ Storage, switching off and control } \\
\hline \multicolumn{3}{|l|}{$\begin{array}{l}\text { function, medium long-term } \\
\text { memory, verbal visual memory) }\end{array}$} \\
\hline \multicolumn{3}{|l|}{ *short term memory disorder only } \\
\hline \multicolumn{3}{|l|}{ * short term memory disorder } \\
\hline \multicolumn{3}{|l|}{ Thinking } \\
\hline *Order and development of thoughts & 16 & 34.0 \\
\hline *Development of attitudes/views & 3 & 27.7 \\
\hline *Tendency to perseveration/confabulation & 8 & 17.0 \\
\hline *Deficient critical performance & 3 & 27.7 \\
\hline *Deficient orientation & 3 & 6.4 \\
\hline \multicolumn{3}{|l|}{ Sensorimotor } \\
\hline *Delay in reaction time & 2 & 4.3 \\
\hline \multicolumn{2}{|l|}{ *Impairment in sensori-motor } & 36.2 \\
\hline \multicolumn{3}{|l|}{ Concentration/ability to take stress } \\
\hline *Concentration disorder & 26 & 55.3 \\
\hline \multicolumn{3}{|l|}{ *Slightly abnormal tendency } \\
\hline to fatigue & 31 & 66.0 \\
\hline $\begin{array}{l}\text { *Considerably abnormal tendency } \\
\text { to fatigue }\end{array}$ & 11 & 23.4 \\
\hline \multicolumn{3}{|l|}{ 2. Personality: } \\
\hline \multicolumn{3}{|l|}{ Drive } \\
\hline \multicolumn{3}{|l|}{ Reduced drive } \\
\hline \multicolumn{3}{|l|}{ Increased drive } \\
\hline Ability to control drive & 9 & 19.1 \\
\hline \multicolumn{3}{|l|}{ Emotionality } \\
\hline \multicolumn{3}{|l|}{$\begin{array}{l}\text { Affectivity, emotional instability, } \\
\text { emotional incontinence, vegetative }\end{array}$} \\
\hline labilisation & 8 & 17.0 \\
\hline General type & 0 & 0 \\
\hline
\end{tabular}


severity, with a six level scale according to the working capacity of the patient for the purposes of occupational accident insurance in the AUVA ${ }^{11}$ (Table 5). On admission/initial examination $27.7 \%$ showed no OPS despite cerebral lesions. $41.6 \%$ of the patients showed very minor to moderate cerebral impairment, $30.7 \%$ of recorded patients were severely disabled regarding cerebral damage.

Figure 2 shows the incidence of cerebral lesions in the different kinds of spinal paralysis. If Figure 2 is classified according to the severity of the OPS, Table 6 will result.

If one considers the multiple deficiencies of spinal paralyzed patients with an associated cerebral lesion as well as the very high proportion of these patients a request must be made for early rehabilitation to treat the brain disorder, which is the pre-condition for the rehabilitation of spinal paralysed patients in cumulative stages. The activities of the psychologist in a centre for spinal paralyzed patients needs to be extended in the neuro-psychological area (Table 7).

Diagnostic measurements of psychological abnormality and also of psychological normality are carried out, ${ }^{12}$ i.e. both the extent of functional disorder and the extent of the remaining functions are established. The neuro-psychological treatment for the present examination group took place taking account of different considerations: It is adapted to the disorders which have been indicated in tests, it establishes a connection from healthy functions to disturbed ones, the patient is active under specialist instructions, it begins at an early stage and is carried out regularly. The performance of the patient must be quantifiable; this assists the psychologist in monitoring the progress of therapy, and also the patient is able to recognize his progress with rehabilitation and find the motivation for further efforts. All treatments-psychological, medical, physiotherapy, ergotherapy, etc. must be coordinated. Different team areas work together with the

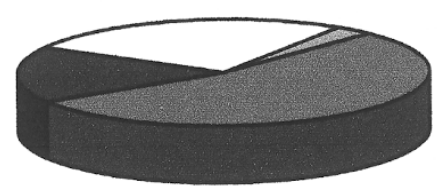

$\square$ paraparesis $n=35$
paraplegia $n=11$
$\square$ tetraparesis $n=17$
$\square$ tetraplegia $n=2$

Figure 2 Incidence of cerebral lesions in paralysed patients

Table 5 Quantification of the organic psychic syndrome (OPS)

\begin{tabular}{|c|c|c|c|}
\hline$O P S$ & Associated impairment & $\mathrm{n}$ & $\%$ \\
\hline $\begin{array}{l}\text { no OPS } \\
\text { very minor }\end{array}$ & $\begin{array}{l}\text { only minor impairment which may be } \\
\text { compensated for during most }\end{array}$ & 18 & 27.7 \\
\hline minor & $\begin{array}{l}\text { occupational activities } \\
\text { generally minor, already considerable }\end{array}$ & 12 & 18.5 \\
\hline moderate & $\begin{array}{l}\text { impairment for some employees } \\
\text { considerable impairment for every }\end{array}$ & 10 & 15.4 \\
\hline medium & $\begin{array}{l}\text { occupational activity } \\
\text { in most cases occupational re-integration }\end{array}$ & 5 & 7.7 \\
\hline higher level & $\begin{array}{l}\text { is not possible } \\
\text { incapacity to work with remaining }\end{array}$ & 12 & 18.5 \\
\hline high level & $\begin{array}{l}\text { capacity for occasional work with light duties } \\
\text { incapacity to work; also incapacity to } \\
\text { carry out occasional simple duties; inadequate } \\
\text { possibility for looking after oneself. }\end{array}$ & 5 & 7.7 \\
\hline & & $n=65$ & $\%=100$ \\
\hline
\end{tabular}

Table 6 Connection between spinal paralysis-severity of the OPS

\begin{tabular}{|c|c|c|c|c|c|c|c|}
\hline & \multicolumn{2}{|c|}{ Paraparesis } & \multicolumn{2}{|c|}{ Paraplegia } & \multicolumn{2}{|c|}{ Tetraparesis } & \multirow{2}{*}{$\underset{\mathrm{n}}{\text { Tetraplegia }}$} \\
\hline & $\mathrm{n}$ & $\%$ & $\mathrm{n}$ & $\%$ & $\mathrm{n}$ & $\%$ & \\
\hline no OPS & 9 & 25.7 & 5 & 45.5 & 4 & 23.5 & - \\
\hline very minor & 5 & 14.4 & 1 & 9.1 & 5 & 29.4 & 1 \\
\hline minor & 4 & 11.4 & 2 & 18.1 & 4 & 23.5 & - \\
\hline moderate & 4 & 11.4 & 1 & 9.1 & - & - & - \\
\hline medium & 9 & 25.7 & 1 & 9.1 & 2 & 11.8 & - \\
\hline higher level & 4 & 11.4 & - & - & - & - & 1 \\
\hline \multirow[t]{3}{*}{ high level- } & - & - & 1 & 9.1 & 2 & 11.8 & - \\
\hline & 35 & 100 & 11 & 100 & 17 & 100 & 2 \\
\hline & & & & & & & $n=65$ \\
\hline
\end{tabular}


Table 7 Psychological treatment strategies for spinal paralysed patients and for spinal paralysed patients with an associated cerebral lesion

\begin{tabular}{|c|c|}
\hline Transverse lesion & $\begin{array}{l}\text { Additional therapies offered for transverse lesion } \\
\text { of the spinal cord with an associated cerebral lesion }\end{array}$ \\
\hline $\begin{array}{l}\text { *crisis intervention } \\
\text { *Psychological and/or psychotherapeutic } \\
\text { care } \\
\text { *Information groups for patients and family } \\
\text { members } \\
\text { *Social skills training } \\
\text { *Methods for the promotion of self therapy } \\
\text { potential (autogenic training, hypnosis, } \\
\text { bio-feedback, etc.) } \\
\text { *Pain control training } \\
\text { *Training for the reduction of disturbing spasticity } \\
\text { *Neuro-muscular re-education (muscle-nerve-system, } \\
\text { breathing, neuro-urology, etc.) }\end{array}$ & $\begin{array}{l}\text { *neuro-psychological diagnosis } \\
\text { *neuro-psychological training: } \\
\text { - paper pencil training } \\
\text { - training with apparatus } \\
\text { - computer assisted training } \\
\text { - neuro-psychological games } \\
\text { which may be used } \\
\text { - practice with learning-memory- } \\
\text { concentration strategies } \\
\text { - training in activities relevant } \\
\text { to every day life. }\end{array}$ \\
\hline
\end{tabular}

psychology department in the treatment of OPS, in particular speech therapy, work therapy and ergotherapy.

After diagnosing partial performance disorders each specific disturbance in the performance area is specially treated using training methods which are precisely adapted to this disorder. ${ }^{9-11}$ Paper pencil training, which as the case requires is set up in a way which is analogous to the tasks in the test used to ascertain mental functions; new training methods are developed in this way. ${ }^{12}$ Apparatus training methods are also used, as well as treatment units using the Viennese determination equipment, ${ }^{10}$ the Viennese concentration equipment 'Cognitrone' or using performance testing equipment. Computer assisted brain performance training, for which there are nowadays a large number of programs for almost all possible specific performance disorders, is particularly motivating in its effect. Training in the group is also carried out using different games which have proved effective in the neuro-psychological treatment of patients with cerebral lesions. ${ }^{12}$ In the case of persisting disorders special assistance is offered with which the person affected learns to compensate for specific performance disorders, and/or to cope with them in everyday life. In the context of this there is special training involving activities which are relevant in everyday life. Personality disorders are treated in individual and in group sessions.

\section{Results}

The duration of the initial psychological treatment of the associated cerebral symptoms of OPS was 12.5 weeks on average $(s=8.5)$. This is somewhat less than the average duration of the rehabilitation of spinal paralyzed patients, which among our patients amounts on average to 16 weeks for those who are paraplegic and 24 weeks for those who are tetraplegic. It is explained by the fact that - as is shown in Table 6 - the cerebral lesion for the most part was combined with paresis (that means a shorter duration of the rehabilitation), and that psychological treatment in individual patients had come to an end before the rehabilitation of the spinal injury, when there was no longer any OPS - which is above all the case for very minor and minor organic psycho syndromes.

The results of treatment and/or the tendency for regression of OPS with envisaged psychological treatment in represented in Table 8 in its quantitative form.

In Table 8 there is a clear shift in the level of severity of OPS, the trend being towards improvement. We did not note any deterioration in any patient-for example as a result of a late complication. $25.5 \%$ of the patients experienced no substantial improvement during the initial rehabilitation. $36.2 \%$ had a substantial improvement, $38.3 \%$ full remission of the organic psychic disorders. The above statements refer to the remission of all organic psychic disorders, that is to OPS overall. If one considers the regression of particular specific disorders during initial rehabilitation, the picture results shown in Figure 3.

While organically based personality changes (in the areas of drive and emotionality) only slightly improved during the initial rehabilitation, an impressive recovery is shown in the area of performance (memory, thinking, sensorimotor, concentration).

\section{Discussion}

With the combination of a transverse lesion of the spinal cord with an associated cerebral lesion there is a combination of different rehabilitation principles. On account of the very high incidence of this compound injury, centres which are primarily set up for spinal paralyzed patients must ensure an adequate programme for this patient group. Based on the experiences which are given here the following needs arise: The rehabilitation of paralyzed patients is made 
Table 8 Regression of organic psycho syndrome after neuro-psychological treatment (duration of treatment $x=12.5$ weeks, $s=8.5)$

\begin{tabular}{|c|c|c|c|c|c|c|c|c|}
\hline $\begin{array}{l}\text { OPS/ } \\
\text { commencement of } \\
\text { treatment }\end{array}$ & $\mathrm{n}$ & none & $\begin{array}{c}\text { OPS/ } \\
\text { titial reh } \\
\text { treatmen } \\
\text { very } \\
\text { minor }\end{array}$ & ion & moderate & medium & higher & high \\
\hline very minor level & 12 & 7 & 5 & - & - & - & - & - \\
\hline minor & 10 & 9 & 1 & - & - & - & - & - \\
\hline moderate & 5 & 2 & 1 & 1 & 1 & - & - & - \\
\hline medium & 12 & - & - & 4 & 6 & 2 & - & - \\
\hline higher & 5 & - & - & - & - & 2 & 3 & - \\
\hline high & 3 & - & - & - & - & - & 2 & 1 \\
\hline Total & 47 & 18 & 7 & 5 & 7 & 4 & 5 & 1 \\
\hline
\end{tabular}

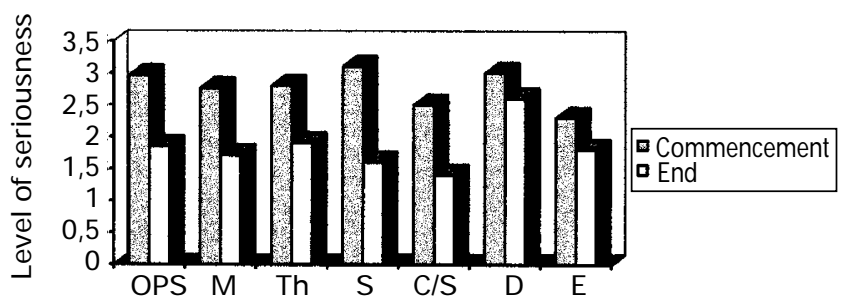

Figure 3 Regression of organic psychic disorders in particular areas of OPS following psychological treatment (Key: $\mathrm{M}$-memory, $\mathrm{Th}$-thinking, $\mathrm{S}$-sensori motor, $\mathrm{C} / \mathrm{S}$ concentration/ability to take stress, D-drive, E-emotionality. Level of seriousness: 1-very minor, 2-minor, 3moderate, 4-medium level, 5-higher level, 6-high level disorders/means)

more difficult because of the psychological effects of cerebral lesions such as disorders in performance and personality. The psychologist working in a centre for spinal paralyzed patients must extend his area of activity to the neuro-psychological area. The possibility of neuro-psychological treatment must follow on from an exact diagnosis made using quantitative and qualitative aspects. Such treatment needs to be specifically adapted to the particular disorders diagnosed. Using a treatment strategy of this type a good remission of performance disorders in the areas of memory, thinking, sensorimotor, and concentration can be achieved, as well as a-even if less clearremission of personality disorders such as disturbances in drive, emotionality and general type. The therapy on offer, as it is available in a centre for spinal paralyzed patients, does not only have to be extended in particular areas, (for example the admittance of brain performance training as part of ergotherapy), it must also be adapted to the patient's abilities (for example, disorders in the area of concentration often have to lead to a shortening of the therapeutic units). Knowledge about specific psychological organic performance and personality disorders therefore lead to an optimization of the success of treatment in the area of those with a spinal transverse lesion. However, it also awakens an understanding of the psychological problems of spinal paralyzed patients, resulting from an associated cerebral injury, which are different to the 'normal' psychological reactions resulting from paralysis from a spinal injury. Dependent on the extent of OPS and capacity to regression the rehabilitation aim must be defined differently. On condition that the stated treatment strategies are modified as necessary for this type of multiple trauma, patients with a very minor to a moderate level of organic psychic syndromes may be rehabilitated to such a degree, that the familiar rehabilitation aims for spinal paralyzed patients may be achieved. The rehabilitation aim for patients with higher to high level organic psychic syndromes must of course be defined here in another way. Occasionally these only amount to expert care, the restoration of as good a physical condition as possible and the training of family members for necessary care provision.

\section{References}

1 Torres F, Shapiro SK. Electroencephalograms in injury: a comparison of electroencephalographic abnormalities with those present in closed head injuries, Arch Neurl 1961; 5: 28 (in English).

2 Junghanns K. The combined injury of the skull and the cervical vertebral column. Monatsschr Unfallheilkunde (Monthly journal on accident medicine 1970; 73: 97 (in German).

3 Meinecke FW. Meaning of specific and overall injury to the vertebral column as the basis for diagnosis in the treatment of injuries to the vertebral column. Unfallmedizinische Tagungen der Landesverbände der gewerblichen Berufsgenossenschaft 1989 (Conference on accident medicine of the regional trade associations); 1: 15 - 30 (in German).

4 Ruidisch MH. Diagnosis and Treatment of secondary injuries. In: Meinecke FW, (ed). Querschnittlähmungen (Transverse lesions with spinal cord injury) Springer: Berlin 1990, pp $72-$ 74 (in German).

5 Schneider T, Mäder M. Traumas to the skull and brain in spinal injuries, medical and social implications in rehabilitation. In: Zäch G A, (ed). Rehabilitation beginnt am Unfallort (Rehabilitation begins at the site of the accident) Springer: Berlin 1991, pp $20-21$. 
6 Strubreither W, Hackbusch B, Stahr G, Jonas HP. Particularities in the rehabilitation of paralysed patients with additional cerebral lesions. In: Jonas HP, Madersbacher H, Strubreither W, (ed). Der polytraumatisierte Querschnittgelähmte. Allgemeine Unfallversicherungsanstalt (The paralysed patient with multiple trauma. General accident insurance company), Vienna 1995, pp $67-71$ (in German).

7 Exner G. What is the level of responsibility of a newly paralysed patient with severe skull-brain trauma? In: Jones HP, Madersbacher H, Strubreither W, (ed). Der polytraumatisierte Querschnittgelähmte Allgemeine Unfallversicherungsanstalt, Vienna 1995, pp 72 - 76 (in German)

8 Mäder M, Hagenbach U. Diagnosis and Treatment Strategies in the early stages of neurological rehabilitation in patients with transverse paralysis and severe brain injury. In: Jonas HP, Madersbacher H, Strubreither W, (ed). Der polytraumatisierte Querschnittgelähmte. Allgemeine Unfallsversicherungsanstalt, Vienna, 1995, pp 59-63 (in German)

9 Scherzer E, Guth E. Rehabilitation following skull-brain trauma. Österr. Ärztezeitung (Austrian Doctor's journal) 1980; 35: 997 (in German).
10 Krösl-Kallinger S. Tasks for clinical psychology in the treatment of patients with skull and brain injuries. In: Egger, J, (ed). Klinische Psychologie in der Rehabilitation. Psychologische Arbeitskonzepte. (Clinical Psychology in rehabilitation. Working concepts in psychology) Literas: Vienna, 1980, pp 25-36 (in German).

11 Wurzer W (1992) Post-traumatic organic psycho syndrome. WUV - Vienna University Press: Vienna, 1992 (in German).

12 Scherzer E (1988) The significance of neuro-psychology in the rehabilitation of injuries to the central nervous system. In: Scherzer E. (ed). Neuropsychologie und Neurorehabilitation. Schlußbericht der Jahrestagung der Österreichischen Gesellschaft für Neurorehabilitation (Neuro-psychology and neuro-rehabilitation). Final report of the Annual conference of the Austrian Association for neuro-rehabilitation. Own publication: Vienna 1988, pp 17-28. 